DOI: $10.12957 /$ teias.\%Y.53705

\title{
DESIGN INSTRUCIONAL:
} perspectiva didático-metodológica para integração da tecnologia na formação docente

\author{
Hiêda Claudia Barbosa Pereira \\ Breno Fabrício Terra Azevedo \\ Paula Carolei
}

\section{Resumo}

A presente pesquisa teve como objetivo propor uma metodologia didático-pedagógica para a disciplina Integração das Mídias e Novas Tecnologias (TDIC), implementada no curso normal em nível médio dos colégios do Estado do Rio de Janeiro, possibilitando contribuir para a formação inicial docente, no que se refere ao uso pedagógico das TDIC. Elaborada por meio de 'Design Instrucional' e disponibilizada no site M.E.N.T.E, a metodologia delineou a estratégia didática e a metodologia ativa que, mediadas por um ambiente virtual de aprendizagem, abordaram temas que propiciam o pensamento crítico durante as aulas. A pesquisa, de cunho qualitativo, adotou a observação participante, pesquisa exploratória, bibliográfica e documental. Como resultado, a partir triangulação dos dados coletados, verificou-se que esta pesquisa proporcionou reflexões acerca da formação interdisciplinar que prioriza a formação do profissional prático e reflexivo, concluindo-se que disponibilizou uma metodologia interdisciplinar que apresentou um paradigma efetivo para a implementação de novas práticas ao trabalho do professor.

Palavras-chave: formação crítico-reflexiva; metodologia didático-pedagógica; design instrucional; tecnologias digitais de informação e comunicação.

INSTRUCIONAL DESIGN: didactic-methodological perspective for integrating technology in teaching training

\begin{abstract}
The present research had as objective to propose a didactic-pedagogical methodology for the discipline Integration of Media and New Technologies (TDIC), implemented in the Normal Course in Medium Level of the colleges of the State of Rio de Janeiro, making possible to contribute for the initial teacher formation, regarding the pedagogical use of TDIC. Elaborated through 'Instructional Design' and made available on the website M.E.N.T.E, the methodology outlined the didactic strategy and the active methodology, which, mediated by a Virtual Learning Environment, addressed themes that provide critical thinking during classes. The research, of qualitative nature, adopted participant observation, exploratory, bibliographic and documentary research. As a result, from the triangulation of the data collected, it was found that this research provided reflections on interdisciplinary training that prioritizes the training of practical and reflective professionals, concluding that it provided an interdisciplinary methodology that presented an effective paradigm for the implementation of new ones. practices to the teacher's work.
\end{abstract}

Keywords: critical-reflective training; didactic-pedagogical methodology; instructional design; digital information and communication technologies. 
DOI: $10.12957 /$ teias. $\%$ Y.53705

DISEÑO INSTRUCIONAL:

perspectiva didáctico-metodológica para integrar tecnología en la formación

docente

Resumen

La presente investigación tuvo como objetivo proponer una metodología didáctico-pedagógica para la disciplina Integración de Medios y Nuevas Tecnologías (TDIC), implementada en el Curso Normal en Nivel Medio de los colegios del Estado de Rio de Janeiro, posibilitando contribuir para la formación inicial docente, sobre el uso pedagógico del TDIC. Elaborada a través de 'Diseño Instruccional', y puesta a disposición en el sitio web M.E.N.T.E, la metodología delineó la estrategia didáctica y la metodología activa, la cual, mediada por un Ambiente Virtual de Aprendizaje, abordó temas que brindan pensamiento crítico durante las clases. La investigación, de carácter cualitativo, adoptó la observación participante, la investigación exploratoria, bibliográfica y documental. Como resultado, a partir de la triangulación de los datos recolectados, se encontró que esta investigación brindó reflexiones sobre la formación interdisciplinaria que prioriza la formación de profesionales prácticos y reflexivos, concluyendo que brindó una metodología interdisciplinaria que presentó un paradigma efectivo para la implementación de nuevos. prácticas al trabajo del maestro.

Palabras clave: formación crítico-reflexiva; metodología didáctico-pedagógica; diseño instruccional; tecnologías de la información y la comunicación digitales.

\section{INTRODUÇÃO}

Acredita-se que a metodologia utilizada nas escolas seja crucial para o sucesso do processo de ensino e aprendizagem, ao mesmo tempo em que é possível perceber que a prática docente está pautada em uma superficialidade do conhecimento direcionada por uma prática de tendências ecléticas, sem objetividade filosófica do que se pretende.

Por conseguinte, abordar o fim da formação de professores em nível médio sem que a formação superior faça parte da realidade de uma totalidade de profissionais, como prevê o Plano Nacional de Educação (PNE) de 2014-2024, parece precoce e incoerente, assim como, decretar o fim do Curso Normal $(\mathrm{CN})$ instantaneamente, poderá deixar de atender às reais necessidades educacionais (FREITAS, 2014). Neste cenário, buscou-se realizar reflexões sobre alguns aspectos curriculares e didático-metodológicos para a integração das TDIC no $\mathrm{CN}$ em nível médio, bem como trazer aos palcos dos debates a formação inicial de professores em nível médio, fazendo uso da revisão da literatura e dos dados analisados.

Nesse contexto, o CN em nível médio dos colégios estaduais do Rio de Janeiro, consolidado como um dos possíveis espaços de formação inicial docente, busca se adequar a essa nova realidade social e, em 2013, implementou na Matriz Curricular a disciplina Integração das Mídias e Novas Tecnologias (IMNT) no $1^{\circ}$ ano do $\mathrm{CN}$, quando passa a dispor do currículo mínimo proposto pela Secretaria de Estado de Educação descrito em forma de competências e habilidades mínimas que os alunos deveriam desenvolver; porém, desprovido de uma proposta metodológica para a disciplina.

Sendo assim, a presente pesquisa, implementada em novembro de 2019, teve como objetivo propor uma metodologia didático-pedagógica para a disciplina IMNT do CN, de forma a contribuir para a formação inicial dos professores, no que se refere ao uso pedagógico das tecnologias digitais, a partir do planejamento elaborado por meio do "Design Instrucional" (DI) adequado à necessidade da Comunidade Escolar em questão. Visa auxiliar na reestruturação do 
DOI: $10.12957 /$ teias. $\%$ Y.53705

trabalho pedagógico da disciplina, flexível e adaptável a diversos contextos, denotando a inter e multidisciplinaridade, a fim de possibilitar transformações e ressignificações contextualizadas.

O processo de DI é composto por um conjunto de ações que iniciam com a identificação de problemas (necessidades) de aprendizagem, e se propõe a projetar, implementar e avaliar uma solução a partir da utilização de métodos, técnicas e atividades de ensino para uma disciplina, apoiadas por tecnologia.

Foram aplicadas ferramentas teórico-metodológicas do DI na concepção pedagógica da disciplina IMNT, cujo aporte teórico baseia-se na teoria sócio-histórica de Vygotsky. O DI 'aberto' foi elaborado por meio do modelo ADDIE. O artigo descreve o percurso metodológico que norteou a elaboração da metodologia por meio das fases deste modelo.

A metodologia da intervenção pedagógica abordou o Currículo Mínimo da disciplina, desenvolvido por meio de Oficinas Pedagógicas Temáticas (OPT) com Temas Contemporâneos Transversais (TCT) previstos na Base Nacional Comum Curricular (BNCC), cujo planejamento está disponível no Google Site (GS) "M.E.N.T.E." - Metodologia de Ensino de Novas Tecnologias, por meio do Mapa e de Matrizes de DI. A proposta elaborada objetivou criar e disponibilizar estratégias pedagógicas focadas nos alunos como protagonistas, utilizando a Aprendizagem Baseada em Problemas (ABP).

A abordagem da pesquisa é qualitativa, por meio de pesquisa exploratória, bibliográfica e documental. Para a coleta dos dados da pesquisa, foram utilizados questionários, entrevistas e observação direta. A partir da triangulação dos dados, verificou-se que esta pesquisa proporcionou reflexões acerca da aquisição de uma formação interdisciplinar que prioriza o profissional prático e reflexivo, disponibilizou uma proposta didático-metodológica que viabiliza a formação para o uso pedagógico das TDIC no contexto no qual ocorre a formação, bem como apresentou um paradigma efetivo para a implementação de novas práticas ao trabalho do professor ao lecionar a disciplina IMNT.

Diante do exposto, a análise dos dados coletados traduz a efetividade da elaboração e implementação da proposta, preocupando-se com averiguar critérios de validade e efetividade da proposta.

\section{A FORMAÇÃO INICIAL DOCENTE E A INTEGRAÇÃO DAS TDIC}

A capacitação dos professores permanece um desafio às políticas públicas que, sem uma efetiva atenção ao desenvolvimento das habilidades que o docente precisa para que as TDIC se integrem às ações pedagógicas, têm mantido o foco no domínio técnico das tecnologias na formação inicial e continuada (CETIC, 2018).

Dessa maneira, visando adequar a formação inicial docente no $\mathrm{CN}$ em nível médio dos colégios estaduais do Rio de Janeiro, às práticas pedagógicas mediadas por TDIC, em 2013, a Secretaria de Educação do Estado do Rio de Janeiro - SEEDUC/RJ - alterou a Matriz Curricular do $\mathrm{CN}$ em nível médio e acrescentou, dentre outras disciplinas, a Integração das Mídias e Novas Tecnologias - IMNT, justificando haver a necessidade de adaptação aos padrões de usos de recursos tecnológicos imprescindível ao exercício profissional, a partir da compreensão de que o trabalho desenvolvido com o uso das tecnologias pode representar uma mudança qualitativa no processo de ensino aprendizagem, determinando que "[...] as unidades escolares que oferecem o curso Normal em nível médio deverão fazer constar em seus Projetos Políticos-Pedagógicos o 
DOI: $10.12957 /$ teias. $\%$ Y.53705

planejamento de Práticas Pedagógicas que favorecessem o uso das tecnologias aplicadas na educação.” (RIO DE JANEIRO, 2013, p.13).

\section{OS DESAFIOS DO CURRÍCULO DO CN E A TEMÁTICA DA PROPOSTA DIDÁTICO-METODOLÓGICA}

Professores dos colégios de $\mathrm{CN}$ são desafiados a projetar uma aprendizagem que integre de forma significativa conteúdo e pedagogia para desenvolvimento de habilidades do século XXI usando tecnologias atuais e emergentes para preparar professores para uma sociedade do conhecimento impulsionada pela tecnologia. É mais do que aprender sobre a tecnologia, é como usá-la (CHAI et al., 2010).

A partir da inserção da disciplina IMNT como Componente Curricular do CN foram propostas novas discussões e estudos das diversas ferramentas tecnológicas e midiáticas no processo ensino-aprendizado, ausentes nas propostas formativas anteriores. A Base Nacional Comum Curricular - BNCC (BRASIL, 2015), reconhece que os Cursos de Formação de professores estão dissonantes da BNCC e acata como verídica a premissa de que há a necessidade de reestruturação dos mesmos.

Diante deste cenário, depreende-se que a prática pedagógica que se efetiva na sala de aula, por meio da metodologia didático-pedagógica, no $\mathrm{CN}$ em nível médio dos colégios estaduais do RJ, encontra-se trilhando a esmo o percurso pedagógico, em face da abordagem atual preconizada nas legislações vigentes, tornando-se necessária a reflexão e o alinhamento da prática pedagógica aos ditames atuais.

Diante da necessidade de adequação dos cursos de formação inicial docente à proposta apresentada na BNCC, verificou-se a necessidade de adequação dos temas a serem tratados no planejamento pedagógico, de elaborar um planejamento que abordasse temas reais, que suscitassem reflexão e que tivessem cunho formativo.

\section{O CURRÍCULO, A BNCC E A TEMÁTICA DA PROPOSTA DE METODOLOGIA DIDÁTICO-PEDAGÓGICA}

Compreende-se que a interrogação ética e a participação crítica constantemente caminhem juntas na formação e desenvolvimento profissional, durante a formação inicial ou no âmbito da formação continuada, fazendo assim com que a educação não seja uma preparação para a vida futura; mas, um processo de viver a educação no presente (DEWEY, 1998).

Assim sendo, é imprescindível que seja promovido o desenvolvimento de competências que preparem para o trabalho; os currículos escolares e os projetos pedagógicos precisam se estruturar de modo que a relação teoria e prática se efetive por meio da relação resolução de problemas da realidade natural e conhecimento teórico, social e cultural (OLIVEIRA, 2019; GALVÃO, 2019), conforme estabelece a BNCC.

Neste contexto, a aula, uma vez considerada como espaço para um processo formativo, estabelece intenções em busca da concretização de ações pedagógicas articuladas com o Projeto Político Pedagógico (PPP) e pautadas no planejamento, implicando na práxis levada a termo por meio de uma organização didática, pressupõe um processo de construção coletiva que emerge de uma realidade concreta e promove o desenvolvimento da colaboração entre os protagonistas, alunos e professores, adotando-se uma visão histórico-crítica de ensino (GALVÃO, 2019). 
DOI: $10.12957 /$ teias. $\%$ Y.53705

O 'currículo mínimo' é a proposta curricular adotada nas escolas públicas estaduais do Estado do Rio de Janeiro. Atendendo ao que determina o currículo mínimo da disciplina IMNT e ao que estabelece a BNCC, também quanto à abordagem de TCT, esta pesquisa, por meio das Oficinas Pedagógicas Temáticas (OPT), visando proporcionar a apropriação do conhecimento teórico por meio da prática, abordou temas apontados na BNCC, que se identificam com o contexto social dos estudantes. Dessa forma, estratégias como a OPT, caracterizam-se por ser um espaço-tempo complexo, cujos participantes são sujeitos e atores, contribuindo para a geração do conhecimento, a partir da cumplicidade entre docentes, alunos e recurso instrucional (RAMALHO, 2019).

Sendo assim, a aula, uma vez considerada como espaço para um processo formativo, estabelece intenções em busca da concretização de ações pedagógicas articuladas com o PPP e pautadas no planejamento, implicando na práxis levada a termo por meio de uma organização didática, pressupõe um processo de construção coletiva que emerge de uma realidade concreta e promove o desenvolvimento da colaboração entre os protagonistas, uma visão crítico-reflexiva, tomando por base os valores éticos e morais e não somente a técnica das TDIC e de seus usos, adotando uma visão histórico-crítica de ensino (GALVÃO, 2019).

Na perspectiva histórico-crítica, o ponto de partida da metodologia não é a escola, nem a sala de aula, mas, numa visão mais a ampla, a realidade social (GASPARIN; PETENUCCI, 2014) nas quais as relações de professor e aluno, ficariam em segundo plano, substituídos pela realidade social, na qual estariam no mesmo patamar e construiriam juntos o conhecimento sobre a mesma.

Neste contexto, buscou-se apresentar uma proposta de metodologia didático-pedagógica para a disciplina IMNT, verificada a ausência de um direcionamento pedagógico, elaborada por meio do Design Instrucional (DI), visando à integração das TDIC na prática pedagógica.

\section{DESIGN INSTRUCIONAL}

O DI, ou Design educacional, é uma metodologia que emergiu em plena segunda guerra mundial, buscando preparar os soldados das forças armadas para melhorar sua atuação em campo; desta forma, procuravam diminuir os gastos com recursos humanos e materiais (MAYER et al., 2001).

Para Filatro (2008), a fim de compreender o conceito de DI, deve-se considerar 'Design' como "resultado de um processo ou atividade (produto)", no que se refere à forma e funcionalidade com intenções definidas e 'instrução' é “[...] a atividade de ensino que se utiliza da comunicação para facilitar a aprendizagem”(2008, p. 3).

Deste modo, para Filatro (2008), DI é a ação intencional de planejar, desenvolver e aplicar situações didáticas contextualizadas com suporte na tecnologia digital, que incorpore, tanto na concepção quanto na implementação, mecanismos que favoreçam a flexibilização da aprendizagem humana.

O DI difere na modalidade presencial, principalmente na mediação didático-pedagógica; ou seja, os processos de ensino e aprendizagem são mediados por TDIC, que são potencialmente relevantes na mediação pedagógica (FILATRO, 2008). Uma distinção foi feita na literatura entre "instrução" e "construção" do conhecimento; com a implicação de que a instrução é necessariamente feita para alunos, enquanto a construção é feita pelos alunos (REIGELUTH, 2009). 
DOI: $10.12957 /$ teias. $\%$ Y.53705

O DI é o desenvolvimento sistemático de especificações instrucionais, utilizando a aprendizagem e a teoria instrucional para garantir a qualidade da instrução; é todo o processo de análise das necessidades e objetivos de aprendizagem e o desenvolvimento de um sistema de entrega para atender a essas necessidades, que inclui desenvolvimento de materiais e atividades instrucionais, bem como teste e avaliação de todas as atividades de ensino e aprendizagem (BROWN, GREEN, 2005).

\section{DI e a elaboração do planejamento}

O modelo de DI que se adequa à presente pesquisa é o 'modelo aberto' segundo as características descritas por Filatro (2008), neste modelo, embora ocorram atividades fora do ambiente on-line, o aluno não consegue participar efetivamente sem acessar a internet; os alunos precisam de estrutura para este acesso e exige do aluno uma postura proativa na garantia de sua aprendizagem. Este modelo privilegia os processos de aprendizagem e pressupõe a participação do educador durante a execução.

Sendo o DI um processo que identifica um problema de aprendizagem que desenha, implementa e avalia uma solução para este problema, percebe-se que ADDIE é o processo mais largamente aceito para este fim, que se divide em pequenas fases interdependentes, representadas por seu acrônimo em inglês para Analysis, Design, Development, Implementation e Evaluation, no qual se separa a 'concepção' do planejamento (análise, Design, desenvolvimento) da 'execução' do mesmo (implementação e avaliação).

\section{A metodologia Ativa}

A aprendizagem baseada em problemas (em inglês Problem Based Learning - PBL), metodologia ativa utilizada nas OPT, é uma abordagem que tem o aluno como protagonista da aprendizagem, que exige que grupos de estudantes explorem problemas do mundo real, valoriza o conhecimento prévio do aluno, considera o professor como um agente reflexivo e colaborativo, enfatiza a autoavaliação, estimula a aplicação do conhecimento fora da escola, prioriza o trabalho em equipe e promove a inovação curricular (BURRIS, GARTON, 2007; SMITH, RAGAN, 2005). Neste contexto, em algum lugar no estágio de integração, uma linha tênue é cruzada e o foco deixa de ser a tecnologia e passa a ser o ensino e a aprendizagem (ROGERS, 2002).

Em ABP, a avaliação atribui aos alunos um papel responsável na análise de seu próprio progresso e dos colegas em seu grupo; além do mais, é fundamental adaptar o processo de avaliação ao tipo de aprendizagem que se deseja alcançar (PINTO et al., 2015). Logo, esta modalidade de planejamento está interessada em uma educação que una os conhecimentos curriculares, favorecendo uma abordagem de problemas interdisciplinar e multidimensional do conhecimento e na aprendizagem, como produto de uma ação educativa, numa junção de conhecimento do conteúdo, tecnológico e pedagógico (MARTINS, 2016).

\section{O planejamento por meio do Design Instrucional}

O diferencial do planejamento por meio do DI encontra-se no equilíbrio entre a automação dos processos de desenvolvimento e a promoção do estudo personalizado em situações didáticas contextualizadas, partindo de uma estrutura matricial norteadora que planeja situações efetivas de construção do conhecimento, de forma interativa e colaborativa, 
DOI: $10.12957 /$ teias. $\%$ Y.53705

identificando o problema de aprendizagem para o qual implementa e avalia uma solução (FILATRO, 2004).

A filosofia educacional para esta aplicação de ADDIE é a de que a aprendizagem deve ser intencional, inovadora, centrada no aluno, autêntica e inspiradora (BROWN, GREEN, 2005). Cada fase tem um resultado que é alimentado na fase subsequente (FILATRO, 2008), como se visualiza na figura 1.

Figura 1: Fases do Processo de DI.

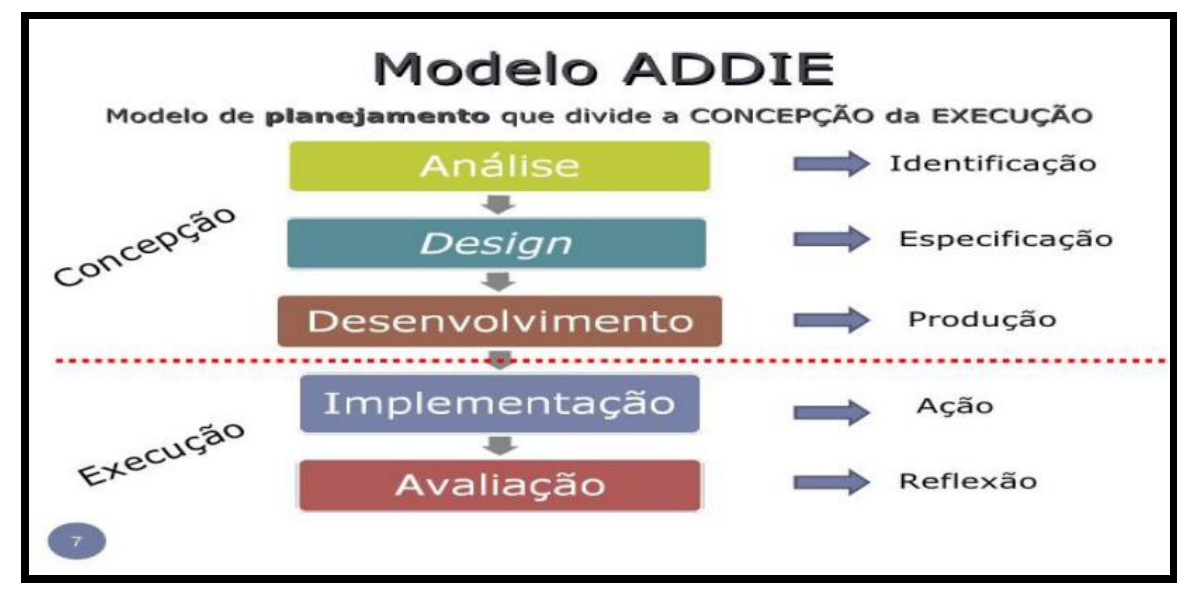

Fonte: Filatro (2008, p. 38).

Com o passar do tempo, os Designers começaram a perceber que, embora fases formem uma boa representação de como o projeto instrucional é trabalhado, o modelo em linha reta com um começo e um fim não era realista; a avaliação do modelo levou a mais análises, que criou a necessidade de redesenho (FILATRO, 2008). Então começa-se a vê-lo como um modelo cíclico.

No modelo ADDIE, a fase da 'análise' envolve compreender o problema educacional e elaborar uma solução por meio do levantamento das necessidades educacionais e da caracterização dos estudantes (FILATRO, 2008). Nesta pesquisa, utilizou-se a pesquisa documental baseada no Currículo mínimo do $\mathrm{CN}$ do Estado do Rio de Janeiro, PPP, BNCC e legislações vigentes.

Nesta pesquisa foi utilizada a estrutura de 'Análise Contextual' sugerida por Filatro e Bileski (2017), que de maneira sistematizada, debruçou-se sobre quatro blocos de interesse para nortear as demais fases do DI e permeia todas as atividades de produção: a identificação de necessidades de aprendizagem, a caracterização do público-alvo e o levantamento de potencialidades e restrições institucionais (FILATRO, BILESKI, 2017).

$\mathrm{Na}$ análise contextual, os dados coletados foram articulados em uma solução única e adequada ao contexto (FILATRO, BILESKI, 2017), permitindo a tradução das teorias de aprendizagem em princípios de Design que orientam o desenvolvimento do produto instrucional (REIGELUTH, 2009). A proposta de metodologia elaborada nesta pesquisa foi delineada pela teoria sócio-histórica de Vygotsky. Nesta perspectiva de construção do conhecimento, considerase central a criação de um ambiente colaborativo permitindo o desenvolvimento de diferentes perspectivas sobre um problema ou realidade, com o desenvolvimento da capacidade de argumentação (BERDNAR et al., 1992). 
DOI: $10.12957 /$ teias. $\%$ Y.53705

Efetuada a análise do contexto, iniciou-se o 'Design' propriamente dito. Nessa fase foi realizado o planejamento da disciplina com definição do conteúdo abordado, identificação dos objetivos educacionais desejados, elaboração das atividades e definição das mídias; por isto deve ser sistematizada e detalhada e para isso sugere-se utilizar os recursos de DI (FILATRO, BILESKI, 2017).

A fase do 'desenvolvimento' no DI aberto, de acordo com Filatro (2008), compreende a produção de recursos adequados e materiais didáticos, bem como a preparação de suporte pedagógico e tecnológico. De acordo com a autora, nesta fase ocorre a preparação prévia das ferramentas a serem utilizadas na execução, tal como a elaboração do conteúdo das oficinas, a determinação dos temas, das situações-problema e ferramentas.

No "DI aberto", durante a 'implementação', ocorre a situação didática na qual se configura o ambiente de aprendizagem (FILATRO, 2008). A seguir ocorre a implementação, na qual é aplicada a proposta de DI e se encontra subdividida em 'publicação' e 'execução'; nela, a publicação disponibiliza as unidades de aprendizagem dos alunos com a configuração das ferramentas. No 'DI aberto', na execução ocorre a situação didática na qual se configura o ambiente de aprendizagem (FILATRO, 2008).

Após esta etapa, segundo Filatro (2008), ocorre a fase da 'avaliação', que analisa a solução educacional quanto aos resultados e adequação de aprendizagem dos estudantes. como as informações serão estruturadas é definido pela estratégia instrucional, assim como define o conteúdo a ser apresentado (FILATRO, 2008).

Sendo assim, a elaboração do DI com base nos conteúdos da disciplina IMNT, visa disponibilizar a proposta didático-metodológica deste projeto, objetivando atribuir uma essência diferenciada ao fazer pedagógico, um fazer com base filosófica sócio-histórica, pautado na metodologia ativa da ABP, levado a termo por meio das Oficinas Pedagógicas Temáticas (OPT).

Fundamentada nestas assertivas, foi elaborada a metodologia didático-pedagógica para a disciplina IMNT, descrita a seguir.

\section{A PROPOSTA DE METODOLOGIA DIDÁTICO-PEDAGÓGICA}

Pretendendo refletir sobre a proposta de um modelo de formação inicial docente construído a partir de uma perspectiva curricular flexibilizada e integrada entre os conteúdos específicos e os conteúdos pedagógicos, e de metodologias inovadoras que têm como foco a formação para a docência emancipatória, numa concepção de ciência e educação interdisciplinar e transversal, parte-se da análise de pressupostos legais e pedagógicos que regem a implementação de um currículo para propor uma metodologia didático-pedagógica para a disciplina IMNT do $1^{\circ}$ ano do $\mathrm{CN}$ em nível médio, elaborada por meio de DI, cujo referencial teórico é a teoria sóciohistórica de Vygotsky.

Assim, a produção didático-pedagógica é uma elaboração teórica que toma um formato prático quando implementada (SILVA, COSTA, 2008). Para os autores, é o resultado de um planejamento baseado em uma concepção de ensino e aprendizagem, com conteúdos e procedimentos teórico-metodológicos específicos do componente curricular em que o professor atua; deve estar condizente com o público a que se destina e buscar possibilidades de solução dos problemas identificados pelos docentes em suas práticas pedagógicas e relatados no projeto de intervenção pedagógica. 
DOI: $10.12957 /$ teias. $\%$ Y.53705

Deste modo, a presente proposta, implementada em novembro de 2019, utilizou as OPT como estratégia, na qual adotou-se a metodologia ativa ABP e o Ambiente Virtual de Aprendizagem - AVA - Google Classroom (GC), disponibilizando o material do planejamento por meio do site construído no Google Site. Nascimento et al. (2007) afirmam que para o processo educacional ser completo, é necessário que o Design e a administração de tecnologias instrucionais como os AVA, venham permitir a colaboração, interação, autonomia e estabelecimento de ritmo individual no processo de execução de tarefas.

Quanto ao material relativo ao planejamento da proposta de metodologia didáticopedagógica para a disciplina IMNT, elaborada por meio de DI (planejamento da proposta pedagógica, tutorial, slides OPT e outros), para apoio ao professor na execução das OPT, poderá ser acessado por meio do site M.E.N.T.E ${ }^{1}$ - Metodologia de Ensino de Novas Tecnologias da Educação, no Google Site'.

Salienta-se que as proposições presentes no site não podem ser entendidas como uma apresentação de modelos prontos para serem colocados em prática, pois destinam-se a provocar reflexões embasadas na realidade de cada comunidade educativa, possibilitando constantes reformulações.

A partir da análise dos problemas, foi possível indicar que o centro da situação que se observa quanto à disciplina IMNT se situa na ausência de uma metodologia didático-pedagógica clara e objetiva, capaz de direcionar a prática pedagógica. Sendo assim, traçou-se a seguinte proposta de metodologia didático-pedagógica pautada no perfil delineado explicitada na tabela 1.

Tabela 1: Proposta de metodologia didático-pedagógica para a disciplina IMNT.

\begin{tabular}{|l|l|}
\hline \multicolumn{2}{|c|}{$\begin{array}{c}\text { METODOLOGIA DIDÁTICO-PEDAGÓGICA PARA A } \\
\text { DISCIPLINA IMNT }\end{array}$} \\
\hline Conteúdo & Currículo Mínimo da disciplina IMNT \\
\hline Teoria da Aprendizagem & Sócio-histórica \\
\hline Estratégia & OPT \\
\hline Abordagem didática & Histórico-crítica e reflexiva \\
\hline Metodologia & Aprendizagem Baseada em Problemas \\
\hline Recursos & AVA (Google Classroom) e demais TDIC \\
\hline Avaliação & Formativa \\
\hline Acesso à proposta & Site M.E.N.T.E. \\
\hline
\end{tabular}

Fonte: Elaboração própria (2020).

A aula pode ser preparada para que o discente participe, associando a sua realidade e construindo saberes na troca de informações, seja com colegas ou com o professor, para construir um conhecimento mais avançado (ARNS, 2019). É nesse sentido que o projeto propõe a OPT como estratégia didática, buscando uma forma de quebrar esse paradigma.

A OPT é conceituada como um espaço de relação entre o conhecimento escolar e o cotidiano dos estudantes, na perspectiva de promover 'habilidades para a vida' por meio da experimentação, criação e expressão autônoma, que em geral, está relacionada a qualquer atividade compartilhada, de natureza prática ou teórico-prática, caracterizada por determinados níveis de participação (CASTILLO, 2012).

\footnotetext{
${ }^{1}$ Disponível em https://sites.Google.com/view/mente-site/página-inicial.
} 
Neste contexto, esta pesquisa selecionou a metodologia ativa da ABP para trabalhar nas OPT, na formação inicial de professores, tomando por base a análise contextual e as várias vertentes em comum entre a metodologia ativa e a estratégia das OPT, apontadas pela literatura (CASTILLO, 2012), nas quais o cotidiano escolar a ser vivenciado pelas estudantes, foi revisitado e problematizado nas atividades propostas, pela ótica do conhecimento científico, atentando aos aspectos sociais, históricos, éticos que possam auxiliar a compreensão do foco que é a situaçãoproblema.

No tocante à utilização do AVA nas OPT, considerando a aprendizagem colaborativa assistida por computador e o conceito de "ambiências formativas" como situações de aprendizagem cocriadas nas quais se articulam os ambientes físicos e digitais onde se dinamizam diversas possibilidades de invenção, de produção intelectual, de constituição de um coletivo que assume, explicita e reinventa seu processo de formação (SANTOS, 2015), criar as ambiências para a mobilização das competências é pensar concretamente em situações que incorporem atualizações ao conhecimento já adquirido, ora gerando novos conhecimentos, ora incorporandoos aos conhecimentos já existentes, a partir da experiência formadora (SANTOS, WEBER, 2013).

Buscando interagir com o professor que leciona a disciplina IMNT, disponibilizando um meio pelo qual possa acessar esta pesquisa e o planejamento elaborado, todo material produzido foi disponibilizado no site. Sendo assim, também é possível ao aluno do $\mathrm{CN}$ ter acesso ao planejamento e participar ativamente do mesmo, assim como é possível solicitar uma cópia do site para que cada professor personalize e adéque o site às necessidades do planejamento pedagógico.

Jaimes et al. (2011) afirmam que a mudança estrutural no desenvolvimento de habilidades e competências, deve ser acompanhada de mudanças na metodologia e na avaliação do processo de ensino-aprendizagem, de modo a incentivar a formação dos alunos, o que demanda modificar o treinamento focado no conteúdo de disciplinas isoladas e no trabalho individual, para uma formação na qual predominam a integração do conhecimento, a atividade do aluno e o trabalho coordenado 
DOI: $10.12957 /$ teias. $\%$ Y.53705

\section{PERCURSO METODOLÓGICO DA PESQUISA}

O percurso metodológico da pesquisa está representado pela figura 2.

Figura 2: Percurso metodológico da pesquisa.

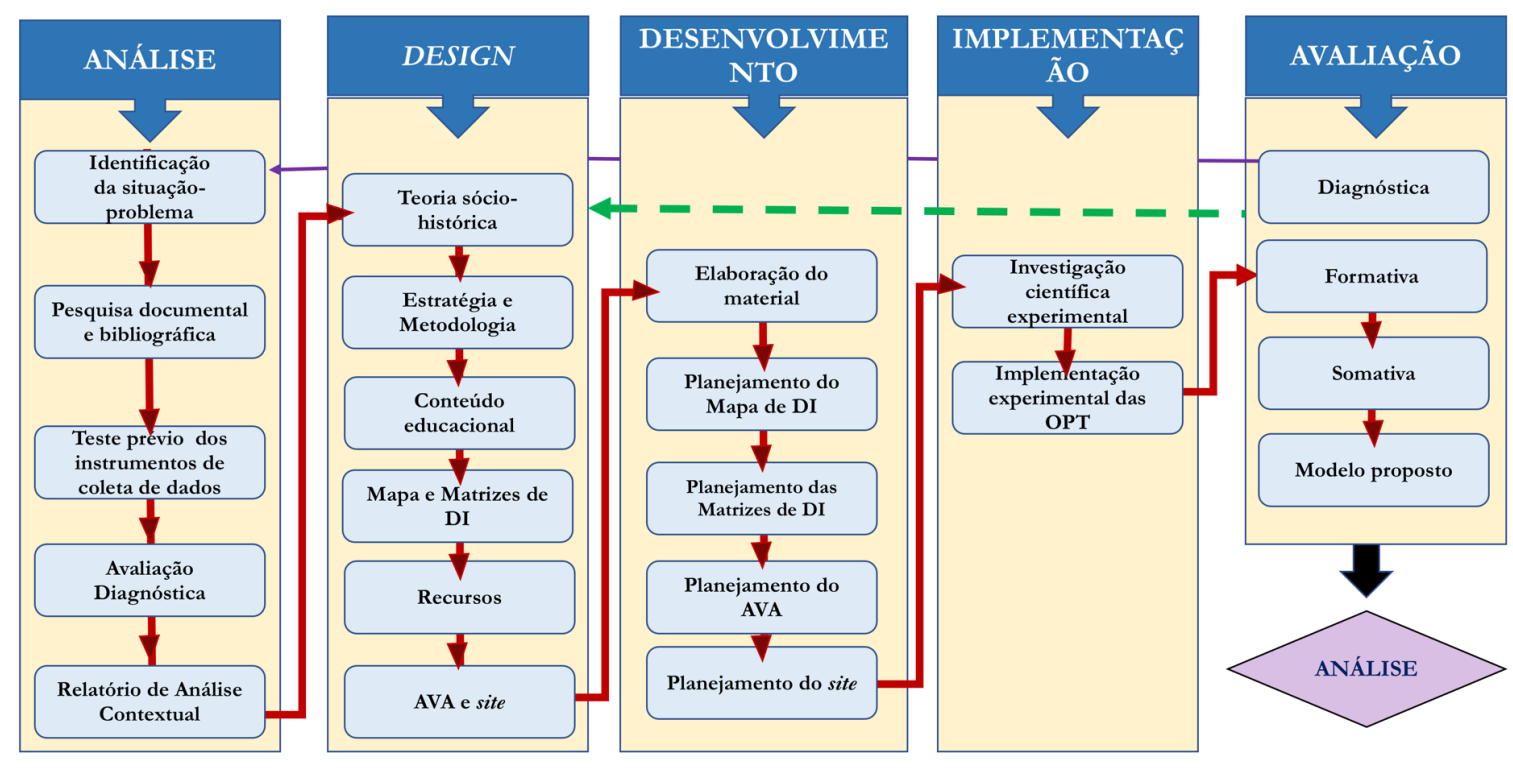

Fonte: Elabora cão própria (2020).

Esta pesquisa, com abordagem qualitativa, objetivou conhecer em profundidade e qualidade uma situação - analisar a adoção de uma proposta de metodologia didático-pedagógica mediada por AVA como interface de apoio à disciplina IMNT do $1^{\circ}$ ano do $\mathrm{CN}$ em nível médio.

A definição dos sujeitos da pesquisa limitou-se aos alunos regularmente matriculados no ano de 2020 nas duas turmas de $1^{\circ}$ ano do $\mathrm{CN}$, com idades de 15 a 18 anos. Destas, dez alunas participaram voluntariamente da pesquisa.

Foram analisados quantitativa e qualitativamente, por meio da análise de conteúdo, os questionários aplicados ao longo da realização da pesquisa. Assim, as repostas passaram pelos processos de categorização e compilação por meio de tabelas e gráficos, que permitiram seu agrupamento e sua discussão, na forma de metatexto.

A partir das fases do Modelo ADDIE, a pesquisa foi desenvolvida em três momentos distintos: $\mathrm{O}$ primeiro momento, que compreende as fases de análise, Design e desenvolvimento do DI, aconteceu antes da situação didática propriamente dita e consistiu na análise do contexto, na elaboração da proposta de Design instrucional aberto e na parametrização do ambiente virtual utilizado e do site.

O segundo momento correspondeu, por meio da implementação da proposta, com a realização de cadastros no AVA, aula de ambientação, aplicação da proposta, acompanhamento e feedback das atividades e intervenções na proposta de DI e no AVA a partir do feedback das alunas.

O terceiro momento correspondeu a última fase do DI: a avaliação das atividades realizadas e da proposta de metodologia didático-pedagógica. Assim, após o término das 
DOI: $10.12957 /$ teias. $\%$ Y.53705

atividades propostas, a partir de um questionário avaliativo aplicado às alunas, entrevista escrita realizada com a professora, os dados foram analisados.

Por meio da observação participante, entrevista, questionário e pesquisa documental, foi possível efetuar uma observação detalhada do contexto e iniciar as etapas do planejamento por meio da elaboração da análise contextual. As informações coletadas foram usadas para informar como o restante do processo de projeto instrucional seria realizado. Coletados os dados, foi realizada a análise que resultou no "relatório de análise contextual", elaborado a partir de informações coletadas e na observação direta.

O passo seguinte ao término da elaboração do problema, foi o processo de Design, centrado no aluno e pautado na teoria sócio-histórica de Vygostky, idealizando as justificativas, determinando as metas, indicando sugestões que colaborassem para a solução do problema detectado e elaborados os objetivos que nortearam as fases seguintes do modelo ADDIE de DI, tendo em vista os principais envolvidos: alunos e professor. Porém, o planejamento almejou ser efetuado de modo que qualquer professor desta disciplina pudesse usufruir deste projeto na sua prática pedagógica que ao se encontrar em situação semelhante.

Baseado na diferenciação que se pode apontar entre o DI e demais formas de planejamento, a elaboração de uma proposta de metodologia didático-pedagógica por meio de DI considera que a tecnologia educacional deixa de ocupar o lugar de "ferramenta" que torna mais eficientes os processos já sedimentados, passando a ocupar o lugar de elemento estruturante das diferentes metodologias educacionais (ROSADO, FERREIRA, 2015).

Com base na leitura dos dados gerados a partir da análise do contexto, descritos anteriormente, iniciou-se a fase de planejamento com o Design das unidades de aprendizagem, que corresponde à fase de Design do DI. Nesse momento, ocorreu o planejamento e foram definidas todas as questões referentes à elaboração do curso, tais como conteúdos, objetivos, estratégias, atividades de aprendizagem e seleção de mídias e recursos, todos gratuitos (FILATRO, BILESKI, 2017).

Nesta perspectiva histórico-crítico e reflexiva, atentando às temáticas abordadas na BNCC, os conteúdos das cinco unidades previamente determinadas no currículo mínimo da disciplina IMNT abordam: Desigualdade Social e Exclusão Digital; Inclusão de alunos com Deficiência Auditiva; Inclusão de alunos com Deficiência Visual; Meio Ambiente e Sustentabilidade; Consumo Consciente e Educação Financeira; Violência nas Escolas; Ciberbullying; Ética social e profissional; Problemas Sociais; Notícias e Fake News.

As unidades, o eixo temático, o foco e os conteúdos a serem trabalhados, foram selecionados e organizados juntamente com a professora de IMNT, de acordo com o que está especificado no currículo mínimo da disciplina IMNT, inclusive no que se refere às habilidades e competências descritas, num total de dez OPT com duração de sete horas-aula cada uma, totalizando 70 horas-aula das 80 horas-aula anuais destinadas à disciplina na atual Matriz Curricular, conforme descrito no Quadro 2.

Desse modo, o objetivo não foi simplesmente transpor para o ambiente digital as práticas didáticas do ensino presencial, mas complementá-las, com recursos diferentes dos utilizados tradicionalmente e com uma abordagem dialética.

$\mathrm{Na}$ fase de Design, foi elaborado o Mapa de DI, obedecendo a sequência das Unidades e o foco e os objetivos gerais que foram estabelecidos pelo currículo mínimo da disciplina IMNT, expressos na forma de habilidade e competências a serem desenvolvidos. Foi planejada a 
elaboração de dez OPT de acordo com a estrutura apresentada no currículo mínimo da disciplina IMNT, demonstradas na tabela 2:

Tabela 2: Conteúdo das OPT.

\begin{tabular}{|c|c|c|c|c|c|c|}
\hline 㸃 & EIXO TEMÁTICO & FOCO & CONTEÚDO & TEMAS & $\begin{array}{l}\text { FERRAMENTAS } \\
\text { DIGITAIS }\end{array}$ & CH \\
\hline \multirow{3}{*}{ 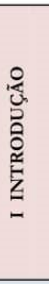 } & \multirow{3}{*}{$\begin{array}{c}\text { AS MÍDIAS E AS } \\
\text { TECNOLOGIAS DA } \\
\text { INFORMAÇÃO } \\
\text { E COMUNICAÇÃO } \\
\text { (TDIC) NA } \\
\text { SOCIEDADE, NA VIDA } \\
\text { E } \\
\text { NA ESCOLA }\end{array}$} & \multirow{3}{*}{ 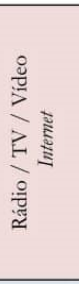 } & $\begin{array}{l}\text { 1. Introdução: Integração de } \\
\text { Mídias e Tecnologias na } \\
\text { Educação - Mídias e } \\
\text { tecnologias na Sociedade. }\end{array}$ & Desigualdade Social e Exclusão Digital & $\begin{array}{l}\checkmark \text { AVA: Google } \\
\text { Classroom } \\
\checkmark \text { Kaboot } \\
\checkmark \text { Educolorir }\end{array}$ & $7 \mathrm{~h} / \mathrm{a}$ \\
\hline & & & 2. Midias Digitais & $\begin{array}{l}\text { Inclusão de alunos com Deficiência } \\
\text { Auditiva }\end{array}$ & $\checkmark$ Moviemaker & $7 \mathrm{~h} / \mathrm{a}$ \\
\hline & & & $\begin{array}{l}\text { 3. Informática e } \\
\text { Interatividade. }\end{array}$ & $\begin{array}{l}\text { Inclusão de alunos com Deficiência } \\
\text { Visual }\end{array}$ & $\begin{array}{l}\checkmark \text { Audacity } \\
\checkmark \text { Os amiguinhos } \\
\checkmark \text { Adivinha sons }\end{array}$ & $7 \mathrm{~h} / \mathrm{a}$ \\
\hline \multirow{3}{*}{ 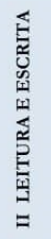 } & \multirow{3}{*}{$\begin{array}{c}\text { PRÁTICAS } \\
\text { PEDAGÓGICAS E } \\
\text { MÍDIAS DIGITAIS }\end{array}$} & \multirow{3}{*}{ 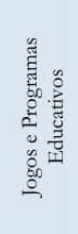 } & $\begin{array}{l}\text { 4. Ferramentas Digitais e } \\
\text { REA }\end{array}$ & Meio Ambiente e Sustentabilidade & $\begin{array}{l}\checkmark \text { REA } \\
\checkmark \text { Sustentabilizando }\end{array}$ & $7 \mathrm{~h} / \mathrm{a}$ \\
\hline & & & $\begin{array}{l}\text { 5. Gamificação e Mídias } \\
\text { móveis }\end{array}$ & $\begin{array}{l}\text { Consumo Consciente e Educação } \\
\text { Financeira }\end{array}$ & $\checkmark$ Minhas finanças & $7 \mathrm{~h} / \mathrm{a}$ \\
\hline & & & $\begin{array}{l}\text { 6. Projetos com mídias } \\
\text { integradas na Educação }\end{array}$ & Violência nas Escolas & $\checkmark$ Canva & $7 \mathrm{~h} / \mathrm{a}$ \\
\hline \multirow{3}{*}{ 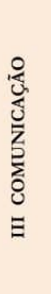 } & \multirow{3}{*}{$\begin{array}{l}\text { COMUNICAÇÃO E } \\
\text { APRENDIZADO }\end{array}$} & \multirow{3}{*}{ 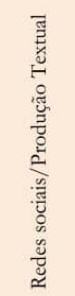 } & $\begin{array}{l}\text { 7. Redes Sociais, Segurança } \\
\text { digital, Cyberbulling }\end{array}$ & Ciberbullying & $\begin{array}{l}\checkmark \text { Facebook } \\
\checkmark \text { Twitter }\end{array}$ & $7 \mathrm{~h} / \mathrm{a}$ \\
\hline & & & $\begin{array}{l}\text { 8. Educomunicação: } \\
\text { Mídia impressa; Produção } \\
\text { de textos (Texto e } \\
\text { Hipertexto; Histórias em } \\
\text { quadrinhos e charges); }\end{array}$ & Ética social e profissional & $\checkmark$ Pixton & $7 \mathrm{~h} / \mathrm{a}$ \\
\hline & & & 9. Mapas e cartografia & Problemas Sociais & $\begin{array}{l}\checkmark \text { Google Earth } \\
\checkmark \text { Google Maps }\end{array}$ & $7 \mathrm{~h} / \mathrm{a}$ \\
\hline $\begin{array}{l}\text { ? } \\
z\end{array}$ & $\begin{array}{l}\text { EDUCAÇÃO } \\
\text { CONTEMPORÂNEA }\end{array}$ & 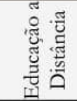 & $\begin{array}{l}10 . \quad \text { Fontes } \\
\text { Confiáveis de Pesquisa }\end{array}$ & $\begin{array}{l}\text { EAD } \\
\text { Notícias e Fake Nens }\end{array}$ & $\checkmark$ Flipsnack & $7 \mathrm{~h} / \mathrm{a}$ \\
\hline
\end{tabular}

Fonte: Elaboração própria (2020).

O planejamento das OPT está estruturado em cinco momentos: $1^{\circ}$ Momento - Introducão; $2^{\circ}$ Momento - Apresentação conceitual e técnica; $3^{\circ}$ Momento - Experimentação; $4^{\circ}$ Momento - Situaçãoproblema e $5^{\circ}$ Momento - Avaliação. Cada momento possui as atividades dispostas e organizadas nas Matrizes de DI, apresentando os objetivos gerais e específicos de cada unidade das OPT - as atividades, o tempo necessário, recursos a serem utilizados e a descrição das atividades a serem desenvolvidas para atingir estes objetivos, com os links para as mídias e/ou textos que podem ser utilizadas pelo professor ao pôr em prática o planejamento.

Após definido o Design, a fase de desenvolvimento que envolve o processo de criação, revisão, produção e validação dos materiais de aprendizagem foi elaborada de modo a ser passível de alteração à medida que novas informações se tornam disponíveis, de modo que as especificações originais sejam ajustadas para acomodar novos requisitos, pois esses ajustes geralmente são aprimoramentos.

Uma vez elaborados o mapa e a matriz de DI e elaborado o Design do site, durante a fase de Design, tornou-se possível desenvolver materiais que seriam apresentados como sugestão para o desenvolvimento das unidades por meio da metodologia didático-pedagógica da disciplina IMNT, a serem desenvolvidas em 70 horas-aula. 
DOI: $10.12957 /$ teias. $\%$ Y.53705

Por se tratar de um curso de formação de professores, considera-se a elaboração do planejamento e a construção coletiva da organização das aulas, como um ato a ser exercitado nas atividades realizadas, por isto, é possível a participação do aluno na elaboração do planejamento acessível no site.

\section{IMPLEMENTAÇÃO DA INVESTIGAÇÃO CIENTÍFICA EXPERIMENTAL}

Nesta fase ocorreu a execução das atividades propostas, fundamentadas no 'relatório de análise contextual', planejadas na fase do 'Design', cujo material foi construído na fase de 'desenvolvimento' do modelo ADDIE.

O DI aberto permite ao professor ajustar o Design inicialmente proposto, a partir de avaliações formais e observações informais da interação. Isso posto, a proposta não se apresenta como um modelo rígido e imutável; pelo contrário, a partir da estrutura apresentada, há uma infinidade de possibilidades de temas e recursos a serem trabalhados de acordo com o contexto no qual será empregado.

\section{Avaliação da implementação experimental das OP'T}

A avaliação, realizada de forma contínua e participativa, compreendeu observar a adequação e funcionalidade das atividades realizadas e o modelo de metodologia proposto e foi formulada de acordo com as necessidades detectadas inicialmente. Portanto, realizado de forma organizada e estimada, de acordo com os parâmetros estabelecidos, permitiu orientar os parâmetros em direção à qualidade.

Nesse sentido, a avaliação desta proposta metodológica foi realizada por meio de critérios, dimensões e indicadores estabelecidos, que valorizaram aspectos-chave como cooperação, colaboração, integração, reflexão e outros, visando à realimentação e ao aprimoramento, que compuseram as rubricas avaliativas.

A avaliação formativa, que acontece simultânea e sequencialmente, foi utilizada em todo o processo de DI para coletar dados que foram usados para fornecer feedback sobre o andamento do processo, embasando as ações de revisão e re-Design do plano. O feedback, obtido por meio de autoavaliação e avaliação por pares baseadas em rubricas avaliativas, permitiu a realização de melhorias na instrução antes que ela fosse completamente desenvolvida.

A fim de explicitar os procedimentos metodológicos da fase de Avaliação do modelo ADDIE e relatar os resultados obtidos, foi elaborado o Relatório de Avaliação. Durante o processo de elaboração e implementação do "modelo ADDIE" para apresentar uma proposta de reestruturação da metodologia da disciplina IMNT, os dados foram coletados e organizados pela pesquisadora para subsidiar a execução das fases de exploração e avaliação. 
Tabela 3: Média das atividades realizadas nas três OPT.

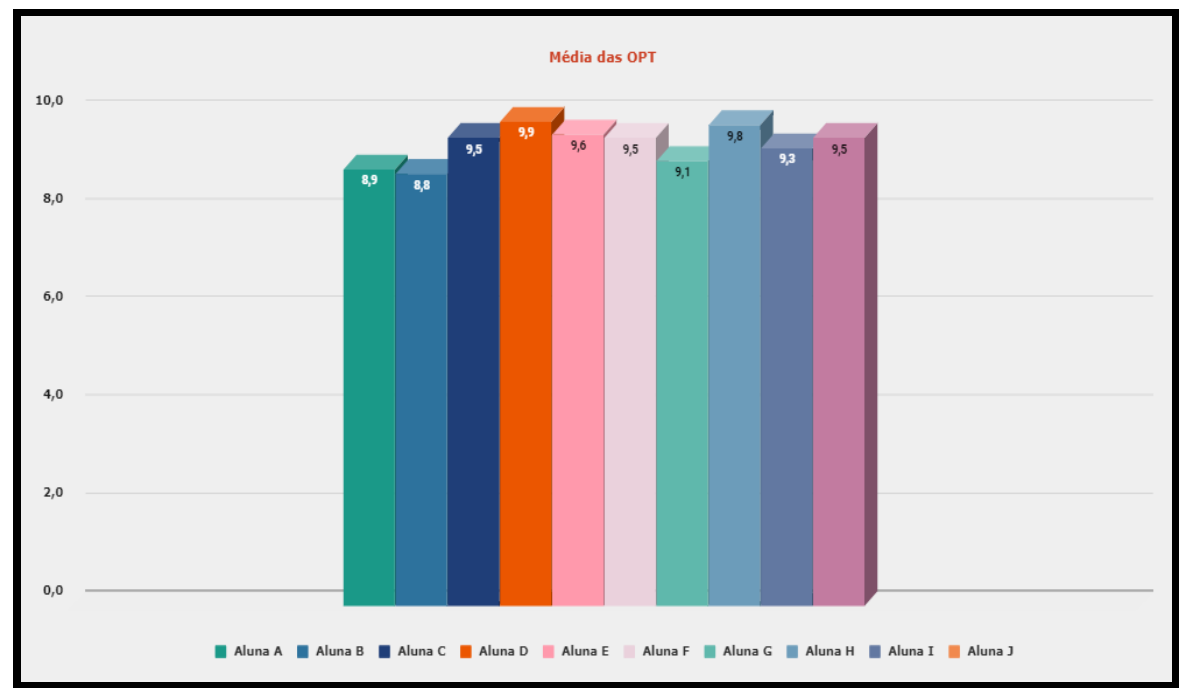

Fonte: Elaboração da própria autora, a partir de dados da pesquisa (2020).

O processo de avaliação da implementação da disciplina utilizando o "modelo ADDIE" correspondeu à análise do modelo propriamente dito e objetivou comprovar a sua pertinência e utilidade para o processo de planejamento estratégico do ensino, assim como para o DI da disciplina do $\mathrm{CN}$ em Nível Médio.

De acordo com dados coletados, obteve-se 94,5\% de aprovação dos participantes quanto às atividades realizadas. Um paradigma focado na aprendizagem do aluno implica em um papel ativo e responsável por parte do discente e dilui a distinção entre o que se pode considerar atividade de aprendizagem e atividade de avaliação. A avaliação é uma atividade embutida no próprio aprendizado, na qual o professor não será o único ator na avaliação, mas um coproprietário da avaliação.

Em resumo, delegar responsabilidades avaliativas aos alunos não apenas os tornou mais ativos em seu aprendizado, como também propiciou que adquirissem competências de auto e heteroavaliação, auto e heterorregulação e auto e heteromotivação, importantes no desempenho profissional.

\section{RESULTADOS E DISCUSSÃO}

Captar os dados a partir de quem foi o foco da pesquisa - o aluno - é de suma importância ao analisar o alcance de objetivos, visto que o feedback recebido do público-alvo, funciona como o início do processo de modificação, inerente da evolução, tornando-se objeto de estudo e pesquisa. Assim, os aspectos que contribuíram para o alcance dos objetivos traçados anteriormente, tende-se a potencializar, enquanto aspectos negativos tendem a passar por reformulação (ROQUE, 2011).

Ao analisar a percepção das participantes a respeito do aspecto formativo das OPT, concluiu-se que a proposta de metodologia apresenta $92 \%$ de aprovação. A partir dos dados coletados, foi possível realizar a análise referente ao modelo implantado quanto à 'formação 
DOI: $10.12957 /$ teias.\%Y.53705

inicial docente para o uso pedagógico das TDIC nos seguintes aspectos: 'construção do conhecimento', 'babilidades', 'competências', 'formação' e 'adequação da metodologia'.

Quanto à 'construção do conhecimento', foi possível verificar que as atividades realizadas por meio da metodologia ativa ABP favoreceram a aprendizagem e contribuíram para a formação profissional, despertando para a busca de mais conhecimento, conforme pretendia-se inicialmente. Quanto às 'babilidades' adquiridas por meio das atividades em grupo e trocas de experiências, verificou-se que a metodologia ativa ABP propiciou o incentivo a busca de conhecimento, favoreceu a aprendizagem e contribuiu na aquisição de conhecimento para qualificação profissional.

No tocante às 'competências' adquiridas, percebe-se que houve a compreensão do papel das TDIC na prática docente e o mais importante, as participantes afirmam que possuem segurança para integrá-las ao planejamento, após a aplicação prática realizada nas OPT. Já a 'formação críticoreflexiva' oportunizada nas OPT, a proposição de atividades coletivas, possibilitou que as participantes pudessem trocar opiniões e pontos de vista a respeito de fatos reais do cotidiano, a respeito da prática pedagógica e de fatos cotidiano que afetam a prática pedagógica. Quanto à análise da 'metodologia' para alcance dos objetivos propostos, conclui-se que é importante, portanto, que o futuro professor conheça e use ferramentas digitais específicas de sua disciplina para ensinar, direcionando um cuidado especial nesta área ao modelar o uso de diferentes ferramentas tecnológicas.

Foi possível compreender, que a abordagem comumente atribuída às aulas pode estar dissociada de questões que afetam diretamente o cotidiano nas diferentes realidades vividas pelas alunas. Concluiu-se que esta proposta se adapta às necessidades da prática pedagógica da disciplina IMNT, apesar de o fato de não ter muito conhecimento em informática.

\section{ALGUMAS CONSIDERAÇÕES}

A instrução em DI pôde ser vista como a criação intencional de condições no ambiente de aprendizagem, que facilitou a consecução de objetivos previamente determinados. Constatouse que a disciplina de IMNT apresentava-se em um cenário contraditório, esvaziado de recursos on-line disponibilizados pelo sistema, mas repletos de criatividade e apropriações tecnológicas perspicazes, frente às ausências existentes.

Há uma discussão que atualmente se inicia a respeito dos processos que suportam as mudanças almejadas serem vitais para o aprendizado e a instrução e que haverá uma visão da integração das TDIC na educação antes e após o fato histórico do isolamento social causado pela COVID-19 em 2020, que provocou um aumento do ensino a distância e uso das TDIC.

A partir da pesquisa realizada, foi possível perceber, assim como apontam Freitas e Forster (2016), que as TDIC podem auxiliar na promoção de um caminho que leve da ingenuidade à criticidade, tornando-se uma ponte para repensar as práticas pedagógicas, visando mais do que usar, mas integrar as TDIC, objetivo da presente proposta de metodologia para a disciplina IMNT.

Deste modo, entendeu-se que é necessário conectar as TDIC às práticas de aprendizagem, interatividade e colaboração entre seus praticantes. Devido à sua natureza participativa e dialógica, as OPT facilitaram a triangulação dos dados coletados, representando um espaço para interpretações compartilhadas em torno das práticas em estudo, além do registro 
sistemático de interações e do estabelecimento das conexões necessárias entre os diferentes níveis de atividade.

Considera-se este estudo como ato de resistência, pois prossegue a pesquisa sobre um componente curricular talvez fadado à extinção, porém em tempo algum banido como prática de formação. Para isso, é necessário que o professor constitua-se de significados, aproprie-se de contexto histórico e de sensibilidade de olhar e de escuta, percebendo-se sim, como responsável pela transformação dos sujeitos que mudam o mundo.

\section{REFERÊNCIAS}

ARNS, Robson Augusto de Souza. Pedagogia Histórico-crítica e aula oficina como proposta prática de Educação Revolucionária. 2019. Trabalho de Conclusão de Curso (Licenciatura em História) Universidade Federal de Integração Latino-Americana (UNILA), Foz do Iguaçu, 2019. Disponível https://dspace.unila.edu.br/bitstream/handle/123456789/5365/Pedagogia $\% 20 H i s t \%$ C3\%B3ric o-Cr $\%$ C $3 \%$ ADtica $\% 20 \mathrm{e} \% 20$ aulaoficina $\% 20$ como $\% 20 \mathrm{uma}^{2} \% 20$ proposta $\% 20 \mathrm{pr}^{0} \% \mathrm{C} 3 \% \mathrm{~A} 1$ tica $\% 20 \mathrm{de} \% 20 \mathrm{educa} \% \mathrm{C} 3 \% \mathrm{~A} 7 \% \mathrm{C} 3 \% \mathrm{~A} 3$ o\%20revolucion $\%$ C3\%A1 ria.pdf?sequence=1\&isAllowed=y. Acesso em 11 fev. 2020.

BEDNAR, Anne K.; CUNNINGHAM, Donald; DUFFY, Thomas Morris et al. Theory into practice: How do we link? In: DUFFY, Thomas Morris; JONASSEN, David. H. (eds.). Constructivism and the technology of instruction: a conversation. Hillsdale, NJ: Lawrence Erlbaum Associates, 1992. Disponível em https://www.goodreads.com/book/show/17768705constructivism-and-the-technology-of-instruction\#_=. Acesso em 11 jan. 2020.

BRASIL. Ministério da Educação. Base nacional comum curricular. Brasília, DF: MEC, 2015. Disponível em http://basenacionalcomum.mec.gov.br/documento/BNCCAPRESENTACAO.pdf. Acesso em 27 jan. 2020.

BROWN, Abbie H.; GREEN, Timothy D. The Essentials of Instructional design: connecting Fundamental Principles with Process and Practice. East Carolina University, Third Edition, 2005. Disponível em https://ikhsanaira.files.wordpress.com/2016/05/the-essential-of-instructionaldesign.pdf. Acesso em 27 jan. 2020.

BUCKWORTH, Jenny. Issues in the teaching practicum. In:The challenge of teaching. Springer, Singapore, $2017 . \quad$ p. $9-17 . \quad$ Disponível https://www.researchgate.net/publication/312000389_Issues_in_the_Teaching_Practicum. Acesso em 20 fev. 2020.

BURRIS, Scott; GARTON, Bryan L. Effect of Instructional Strategy on Critical Thinking and Content Knowledge: Using Problem-Based Learning in the Secondary Classroom. Journal of Agricultural Education, v. 48, n. 1, p. 106-16, 2007. Disponível em http://www.jaeonline.org/attachments/article/193/Burris_Garton_48_1_106-116.pdf. Acesso em 24 jan. 2020.

CASTILLO, Sandra Soler. Lenguaje y Educación: Perspectivas metodológicas y teóricas para su estudio. Universidad Distrital Francisco José de Caldas. Bogotá, Colombia, 2012. Disponível em https://www.academia.edu/20109717/Lenguaje y Educaci\%C3\%B3n Perspectivas metodol\%C 3\%B3gicas y te\%C3\%B3ricas para su estudio. Acesso em 12 jan. 2020.

CHAI, Ching Sing; KOH, Joyce Hwee Ling; TSAI, Ching-Chung. Facilitating Preservice Teachers' Development of Technological, Pedagogical, and Content Knowledge (TPACK). 
DOI: $10.12957 /$ teias. $\%$ Y.53705

Educational Technology \& Society, v. 13, n. 4, p. 63-73, 2010. Disponível em https://www.jstor.org/stable/jeductechsoci.13.4.63?seq=1https://www.jstor.org/stable/jeducte chsoci.13.4.63? seq=1. Acesso em 22 jan. 2020.

DEWEY, John. Como pensamos: Nueva exposición de la relación entre pensamiento y proceso educativo. Paidos, 1998. Disponível em file:///C:/Users/HCBPAV/Desktop/5605aa comopensamos.pdf. Acesso em 29 jan. 2020.

FILATRO, Andrea Cristina. Design Instrucional Contextualiz̧ado: educação e tecnologia. São Paulo: Editora SENAC, 2004.

FILATRO, Andrea Cristina. Design Instrucional na prática. São Paulo: Pearson Education do Brasil, 2008.

FILATRO, Andrea Cristina; BILESKI, Sabrina M. Cairo. Produção de conteúdos educacionais. São Paulo: Saraiva, 2017.

FREITAS. Helena Costa Lopes de. PNE e formação de professores Contradições e desafios. Revista Retratos da Escola, Brasília, v. 8, n. 15, p. 427-46, jul./dez. 2014. Disponível em https://www.esforce.org.br. Acesso em 5 fev. 2020.

GALVÃO, Ana Carolina; LAVOURA, Tiago Nicola; MARTINS, Lígia Marcia. Fundamentos da Didática Histórico-crítica. $1^{\mathrm{a}}$ ed. Campinas, SP: Autores Associados, 2019.

JAIMES, Rinarda Betancourt; MURILLO, Leidy Nattali Guevara; RAMÍREZ, Eliana Mayling Fuentes. El taller como estrategia didáctica, sus fases y componentespara el desarrollo de un proceso de cualificación en el uso detecnologias de la información y la comunicación (tic) condocentes de lenguas extranjeras.caracterización y retos. Universidad de la Salle. Facultad de Ciencias de la Educación. 2011. Disponível

https://ciencia.lasalle.edu.co/cgi/viewcontent.cgi?article=1304\&context=lic lenguas. Acesso em 30 jan. 2020.

MAYER, Richard; HEISER, Julie; LONN, Steve. Cognitive constraints and multimedia learning: when presenting more material results in less understanding; Journal of education psychology. 2001, vol. 93, n. $1, \quad$ p.187-198. 1 Disponível em https://www.researchgate.net/publication/232530555 Cognitive Constraints on Multimedia Learning When Presenting_More Material Results in Less Understanding. Acesso em 13 jan. 2020.

PAIVA, Deise de Lacerda. A Base Nacional Comum Curricular (BNCC) e a Utilização das TIC na Educação. Pesquisa sobre o uso das tecnologias de informação e comunicação nas escolas brasileiras [livro eletrônico]. São Paulo: Comitê Gestor da Internet no Brasil, 2017. Disponível em https://www.cetic.br/media/docs/publicacoes/2/TIC EDU 2016 LivroEletronico.pdf.

Acesso em 1 abr. 2019.

RAMALHO, Maria Luiza Dias. De coadjuvante a protagonista: a formação de professores em educação musical no contexto da educação infantil-uma experiência com as Oficinas Pedagógicas da SEDF, 2019. Disponível em http://repositorio.se.df.gov.br/bitstream/123456789/1125/1/2016 MariaLuizaDiasRamalho.pd f. Acesso em 12 fev. 2020.

REIGELUTH, Charles Morgan. Design Theories and Models. NYBuilding a Common Knowledge BaseEditedby. 2009. v. III. 
DOI: $10.12957 /$ teias. $\%$ Y.53705

RIO DE JANEIRO. SEEDUC/RJ. Resolução SEEDUC No 5330/2015. Matriz Curricular do Curso Normal das Escolas Estaduais, Diário Oficial do Estado do Rio de Janeiro, 10 set. 2015. Disponível em http://www.silep.planejamento.ri.gov.br/resolucao_seeduc n 5 330_-_102.htm. Acesso em 10 mai. 2019.

ROGERS, Patricia L. Designing Instruction for Technology-enhanced Learning. Hershey, PA: Idea Group Publishing, 2002. Disponível em https://iums.ac.ir/files/hshesoh/files/2.\%5BPatricia L. Rogers \%5D Designing Instruction for Tec(BookFi.org).pdf.

Acesso em 21 jan. 2020.

ROQUE, Gianna Oliveira Bogossian. Metodologia para avaliação e acompanhamento de cursos a distância: em busca da qualidade. In: $17^{\circ}$ CIAED - Congresso Internacional ABED de Educação a Distância, Manaus, 2011. Disponível em http://www.abed.org.br/congresso2011/cd/155.pdf. Acesso em 16 fev. 2020.

ROSADO, Luiz Alexandre da Silva; FERREIRA, Giselle Martins dos Santos. Educação e tecnologia: parcerias. v. 4 [livro eletrônico]. Rio de Janeiro: Editora Universidade Estácio de Sá, 2015. Disponível em https://www.academia.edu/18396839/Educa $\% \mathrm{C} 3 \% \mathrm{~A} 7 \% \mathrm{C} 3 \% \mathrm{~A} 3 \mathrm{o}$ e tecnologia parcerias volu me 4. Acesso em 11 fev. 2020.

SANTOS, Edméa; WEBER, Aline. Educação e cibercultura: aprendizagem ubíqua no currículo da disciplina didática. Revista Diálogo Educacional, v. 13, n. 38, p. 285-303, 2013. Disponível em: https://periodicos.pucpr.br/index.php/dialogoeducacional/article/view/8042. Acesso em 11 fev. 2020.

SANTOS, Rosemary dos. Formação de Formadores e Educação Superior na cibercultura: itinerâncias de Grupos de Pesquisa no Facebook. 2015. 183 f. Tese de Doutorado em Educação - Faculdade de Educação, Universidade do Estado do Rio de Janeiro, Rio de Janeiro, 2015. Disponível em http://www.proped.pro.br/teses/teses_pdf/2010_1-505-DO.pdf. Acesso em 22 jan. 2020.

SMITH, Patricia; RAGAN, Tillman. A framework for instructional strategy design. In: SMITH, Patricia; RAGAN, Tillman (Eds.). Instructional design, 3rd ed. New York, NY: Wiley \& Sons, 2005. p. 127-50. Disponível em https://spip.teluq.ca/ted6210 v3/IMG/pdf/TED6210 Smith 2005.pdf. Acesso em 11 fev. 2020. 


\section{Informações dos autores:}

Prof ${ }^{a}$ MEd. Hiêda Claudia Barbosa Pereira.

Instituto Federal Fluminense (IFF) Campus Campos Centro/RJ - Mestrado Profissional em Educação e Suas Tecnologias.

E-mail: advogy@gmail.com.

ORCID: https://orcid.org/0000-0003-1543-2175

Link Lattes: http://lattes.cnpq.br/9889792921695077.

Prof. Dr. Breno Fabrício Terra Azevedo.

Instituto Federal Fluminense (IFF) Campus Campos Centro/RJ

E-mail: bterra@iff.edu.br.

ORCID: https://orcid.org/0000-0002-3034-8476.

Link Lattes: http://lattes.cnpq.br/1270275195280528.

Prof $^{a}$ Dra. Paula Carolei.

Universidade Federal de São Paulo (UNIFESP)

E-mail: pcarolei@gmail.com.

ORCID: https://orcid.org/0000-0002-1592-9731.

Link Lattes: http://lattes.cnpq.br/0778199387503922. 